\title{
Validity and reliability of the Disabilities of Arm, Shoulder, and Hand scale in dental students: A transnational study
}

\section{Danielle Wajngarten, Juliana Alvares Duarte Bonini Campos, Ana Carolina} Botta \& Patrícia Petromilli Nordi Sasso Garcia

To cite this article: Danielle Wajngarten, Juliana Alvares Duarte Bonini Campos, Ana Carolina Botta \& Patrícia Petromilli Nordi Sasso Garcia (2018) Validity and reliability of the Disabilities of Arm, Shoulder, and Hand scale in dental students: A transnational study, Archives of Environmental \& Occupational Health, 73:4, 258-266, DOI: 10.1080/19338244.2017.1328384

To link to this article: https://doi.org/10.1080/19338244.2017.1328384

Accepted author version posted online: 10

May 2017.

Published online: 30 May 2017.

Submit your article to this journal ¿

Џ Article views: 96

View Crossmark data ¿ 


\title{
Validity and reliability of the Disabilities of Arm, Shoulder, and Hand scale in dental students: A transnational study
}

\author{
Danielle Wajngarten (1D ${ }^{a}$, Juliana Alvares Duarte Bonini Campos ${ }^{\mathrm{b}}$, Ana Carolina Bottac, \\ and Patrícia Petromilli Nordi Sasso Garcia ${ }^{\mathrm{d}}$

\begin{abstract}
${ }^{\mathrm{a}}$ Araraquara Dental School, Universidade Estadual Paulista (UNESP), Araraquara, São Paulo, Brazil; ${ }^{\mathrm{b}}$ Department of Food and Nutrition, Araraquara College of Pharmaceutical Sciences, Universidade Estadual Paulista, Araraquara (UNSEP), São Paulo, Brazil; 'Department of General Dentistry, Stony Brook School of Dental Medicine, New York, New York, USA; ${ }^{d}$ Department of Social Dentistry, Araraquara Dental School, Universidade Estadual Paulista (UNESP), Araraquara, São Paulo, Brazil
\end{abstract}

\begin{abstract}
This study aimed to evaluate the validity and reliability of the Disabilities of Arm, Shoulder, and Hand (DASH) scale in Brazilian and American dental students and assess the influence of demographic variables on disability in them. A cross-sectional observational study was conducted with a nonprobabilistic sample. The sample was composed of students of both genders from the School of Dentistry of Araraquara, State University of São Paulo (UNESP) $(n=288)$, and students from Stony Brook University, New York, NY, USA $(n=149)$. The disabilities of the upper limbs were estimated using the DASH scale. The samples were characterized by collecting information on gender, academic year, and sports and work activities. The refined bifactorial model presented goodness-of-fit indices for both countries. There was a significant effect of the variables gender and academic year for the Brazilian sample and the variable sports practices for the American sample. The refined bifactorial model was valid and reliable for the Brazilian and American populations. In this model, the removal of item 17 for the Brazilian sample and items 3, 13, and 23 for the American sample was necessary. Demographic variables such as gender, academic year, and sports practice contributed significantly to the level of disability in the study populations.
\end{abstract}

\section{ARTICLE HISTORY}

Received 18 October 2016 Accepted 5 May 2017

\section{KEYWORDS}

DASH; dental students; ergonomics; musculoskeletal disorders; upper extremity
Work-related musculoskeletal disorders are a public health problem because they may lead to disability. ${ }^{1,2}$ These injuries primarily affect the upper limbs. ${ }^{3}$ There are several methods to measure disability among individuals, such as clinician-administered tools, clinician observations, and self-report instruments. ${ }^{4}$ Self-report methods have been recommended to measure disability in a large number of people $e^{5-8}$ because they require less time $^{9}$ and are less costly than objective methods.

The Disabilities of the Arm, Shoulder, and Hand (DASH) scale is a self-report questionnaire that has been developed to quantify disability, particularly in terms of physical functioning, and symptoms in a wide variety of upper-extremity conditions. ${ }^{10}$ This instrument was originally composed of 30 items arranged in a unifactorial theoretical structure and is based on physical, social, and psychological theory.
The DASH questionnaire quantifies disability and symptoms that are abstract or theoretical constructs. Thus, its psychometric properties need to be evaluated to ensure the reliability and validity of the data obtained. ${ }^{11}$ These psychometric measurements are correlated specifically with the population evaluated and are not a characteristic of the instrument. ${ }^{11-13}$

The DASH scale has been used in various countries to measure disability in individuals in different occupations and in patients clinically diagnosed with diseases of the musculoskeletal system. ${ }^{3,14-22}$ However, to date, this instrument has not been applied to dentists and dental students, who are highly susceptible to musculoskeletal diseases of the upper limbs. ${ }^{10,23-26}$

Therefore, this study aimed to evaluate the validity and reliability of the DASH scale with Brazilian and American students and assess the influence of gender and academic year on disability, sports practices, and work activities on their musculoskeletal functioning.

CONTACT Patrícia Petromilli Nordi Sasso Garcia $\otimes$ psgarcia@foar.unesp.br Department of Social Dentistry, Araraquara Dental School, Universidade Estadual Paulista (UNESP), Rua Hemaitá, 1680. CEP: 14801-903 Centro, Araraquara, São Paulo, Brazil.

Color versions of one or more of the figures in the article can be found online at www.tandfonline.com/vaeh. 


\section{Methods}

\section{Study design and population}

This cross-sectional observational study was conducted with a nonprobabilistic sample. The sample was composed of students of both genders from the School of Dentistry of Araraquara, State University of São Paulo (UNESP) $(n=288)$, and from Stony Brook University, New York, New York, USA $(n=149)$.

$\mathrm{Kim}^{27}$ suggested the calculation of a minimum sample size by the power of the test. Therefore, considering an alpha of $5 \%$, power of $80 \%$, and the degrees of freedom of the model $(\mathrm{df}=404)$, the minimum sample size estimated for this study was 77 participants in each group. The present study was also educational; therefore, all students were encouraged to participate. Consequently, the sample size was higher than the minimum sample size calculated, and it did not compromise the analyses. However, if the sample size was lower than the minimum sample size, the analyses could have been compromised.

\section{Variables and tools}

The samples were characterized by collecting information on gender, academic year, and sports and work activities. The disabilities of the upper limbs were estimated using the DASH scale.

The DASH instrument was adapted to Brazilian Portuguese by Orfale et $\mathrm{al}^{20}$ and was used to measure the disability of the arms, shoulders, and hands in Brazilian students. The original version in English was proposed by Hudak et $\mathrm{al}^{7}$ and used for American students. Both versions were composed of 30 items, with a 5 -point Likert scale $(1=$ no difficulty; $5=$ unable $)$.

This study tested 3 different factorial models. The first model was a trifactorial structure based on the theoretical concept used by the Upper Extremity Collaborative Group (UECG) in the development of the DASH scale. ${ }^{28}$ According to the scale developers, disabilities related to the upper limbs are measured on three aspects: physical function, symptoms, and social function. The second model was a bifactorial structure, where the physical function and the symptoms/social function were assessed. The third model was a unifactorial structure, considered as a reference by the UECG when applied to a sample of individuals with different musculoskeletal disorders. ${ }^{28}$

\section{Data collection and ethical considerations}

The self-report instrument was completed by the students in the classroom, in the presence of the researcher. The present study was approved by the Human Research Ethics Committee of the School of Dentistry of Araraquara at UNESP
(CAAE No. 26051513.5.0000.5416) and the School of Dentistry at Stony Brook University (CORIHS \#2014-2839-F).

\section{Statistical analysis}

\section{Psychometric sensitivity}

Psychometric sensitivity was evaluated using measurements of summary and shape. Sensitivity was considered appropriate when skewness was $<3$ and kurtosis was $<7$, in terms of their absolute values. ${ }^{29}$

\section{Construct validity}

The construct validity of the DASH scale was estimated by determining the factorial and convergent validities. A confirmatory factorial analysis (CFA) was performed to estimate the factorial validity using a polychoric correlation matrix and MPLUS software version 6.0 (Muthén and Muthén, Los Angeles, CA, USA). The Tucker-Lewis index (TLI), goodness-of-fit index (GFI), root mean square error of approximation (RMSEA), and chi-square/degrees of freedom ratio $\left(\chi^{2} / \mathrm{df}\right)$ were used as indices of the quality of fit. The overall fit was considered appropriate if $\chi^{2} / \mathrm{df} \leq 4.0$, TLI $\geq 0.90$, GFI $\geq 0.90$, RMSEA $\leq 0.10$, and $\lambda \geq 0.40 .{ }^{11}$ In cases in which appropriate indices were not obtained, the structure was refined using Lagrange multipliers $(<11) .^{30}$

Convergent validity was estimated using the average extracted variance (AVE), ${ }^{11}$ and this variable was considered appropriate if $\mathrm{AVE}_{j} \geq 0.50$.

The discriminant validity was estimated by correlation analysis ${ }^{11}$ between the factors and was considered adequate if AVEi and $A V E j \geq$ rij. ${ }^{14}$

\section{Internal consistency}

Internal consistency was calculated using the standardized Cronbach's alpha coefficient $(\alpha)$ and the composite reliability (CR) and was considered appropriate when $\alpha \geq$ 0.70 and $\mathrm{CR}_{j} \geq 0.70 .{ }^{11}$

\section{Causal model}

A causal model was developed using structural equation modeling to assess the influence of gender, academic year, sports practices, and work activities on scores on the DASH scale of dental students. The model was evaluated in 2 stages using the MPLUS software version 6.0 (Muthén and Muthén). During the first stage, the quality of fit of the model was evaluated using the $\chi^{2} / \mathrm{df}$, the comparative fit indices (CFIs), TLI, and RMSEA. The model fit was considered appropriate using the same parameters adopted in the instrument validation process. ${ }^{11}$ During the second stage, the contribution $(\beta)$ and significance of causal trajectories were evaluated using the $Z$ test. The significance level was determined to be $5 \%$. 
Table 1. Assessment characteristics of the participating students.

\begin{tabular}{|c|c|c|c|c|c|c|}
\hline \multirow[b]{3}{*}{ Variable } & \multicolumn{6}{|c|}{ Country } \\
\hline & \multicolumn{2}{|c|}{$\begin{array}{c}\text { Brazil } \\
n=288\end{array}$} & \multicolumn{2}{|c|}{$\begin{array}{c}\text { United States } \\
\quad n=149\end{array}$} & \multicolumn{2}{|c|}{$\begin{array}{c}\text { Total } \\
N=437\end{array}$} \\
\hline & $n$ & $\%$ & $n$ & $\%$ & $n$ & $\%$ \\
\hline \multicolumn{7}{|l|}{ Gender } \\
\hline Female & 218 & 75.7 & 82 & 55.0 & 300 & 68.6 \\
\hline Male & 70 & 24.3 & 67 & 45.0 & 137 & 31.4 \\
\hline \multicolumn{7}{|l|}{ Academic year } \\
\hline 1st & 57 & 19.8 & 41 & 27.5 & 98 & 22.4 \\
\hline 2nd & 64 & 22.2 & 39 & 26.2 & 103 & 23.6 \\
\hline $3 r d$ & 65 & 22.6 & 37 & 24.8 & 102 & 23.3 \\
\hline 4th & 53 & 18.4 & 32 & 21.5 & 85 & 19.5 \\
\hline 5th & 49 & 17.0 & - & & 49 & 11.2 \\
\hline \multicolumn{7}{|l|}{ Sport activities } \\
\hline No & 126 & 43.8 & 44 & 29.5 & 170 & 38.9 \\
\hline Yes & 162 & 56.3 & 105 & 70.5 & 267 & 61.1 \\
\hline Work activities & & & & 87.2 & & \\
\hline No & 254 & 88.2 & 130 & & 384 & 87.9 \\
\hline Yes & 34 & 11.8 & 19 & 12.8 & 53 & 12.1 \\
\hline
\end{tabular}

\section{Results}

Table 1 presents the demographic characteristics of the study populations.

We observed that in Brazil and the United States, most study samples were composed of female students who practiced sports but did not perform work activities.
Table 2 presents the measurements of summary and shape of distributions of DASH's items.

The average values of the DASH scale items varied between 1.040 ( \pm 0.209) and 2.280 ( \pm 1.095). Regarding skewness and kurtosis, the values of items 13 and 17 , respectively, were higher than the recommended values.

Table 3 presents the goodness-of-fit indices according to the factorial structure of the countries evaluated.

We observed that the trifactorial structure of both samples presented multicollinearity between 2 factors $\left(r_{\mathrm{Brazil}}=1.021 ; r_{\mathrm{USA}}=0.985\right)$. The complete model used in the United States was not refined, despite the poor fit (Table 2), whereas the complete model used in Brazil presented a good fit and was not refined. With respect to the bifactorial structure, the complete models used in these 2 countries did not present a good fit. Therefore, both models were refined. The complete and refined models did not present a good fit in the unifactorial structure. Regarding convergent validity, AVE was close to or within values considered appropriate $(\mathrm{AVE} \geq 0.5)$ and $\mathrm{CR}$ was within values considered appropriate (CR $\geq$ 0.7 ) for all structures evaluated in Brazil and the United States. Discriminant validity was limited only in the trifactorial structure, for both countries. The internal consistency was also close to values considered appropriate

Table 2. Psychometric sensitivity of the DASH instrument.

\begin{tabular}{|c|c|c|c|c|c|c|c|c|c|c|c|c|}
\hline \multicolumn{13}{|c|}{ Samples } \\
\hline \multirow[b]{2}{*}{ Item } & \multicolumn{3}{|c|}{ Mean } & \multicolumn{3}{|c|}{ Standard deviation $( \pm)$} & \multicolumn{3}{|c|}{ Skewness } & \multicolumn{3}{|c|}{ Kurtosis } \\
\hline & Brazil & USA & Total & Brazil & USA & Total & Brazil & USA & Total & Brazil & USA & Total \\
\hline 01 & 2.280 & 1.660 & 2.070 & 1.095 & 0.812 & 1.049 & 0.545 & 0.936 & 0.736 & 0.429 & 0.138 & 0.175 \\
\hline 02 & 1.100 & 1.100 & 1.100 & 0.387 & 0.398 & 0.390 & 4.635 & 4.739 & 4.657 & 25.568 & 25.412 & 25.210 \\
\hline 03 & 1.040 & 1.060 & 1.050 & 0.209 & 0.266 & 0.230 & 5.943 & 4.767 & 5.445 & 38.663 & 24.582 & 32.181 \\
\hline 04 & 1.120 & 1.180 & 1.140 & 0.409 & 0.494 & 0.440 & 3.928 & 2.756 & 3.415 & 16.796 & 6.701 & 11.865 \\
\hline 05 & 1.670 & 1.460 & 1.590 & 0.733 & 0.631 & 0.706 & 0.774 & 1.065 & 0.878 & 0.173 & 0.062 & 0.057 \\
\hline 06 & 1.350 & 1.330 & 1.340 & 0.606 & 0.672 & 0.628 & 1.647 & 2.203 & 1.871 & 2.014 & 4.563 & 3.093 \\
\hline 07 & 1.690 & 1.350 & 1.570 & 0.825 & 0.614 & 0.776 & 0.966 & 1.571 & 1.168 & 0.940 & 1.322 & 0,524 \\
\hline 08 & 1.780 & 1.430 & 1.660 & 0.959 & 0.710 & 0.896 & 1.103 & 1.921 & 1.340 & 0.512 & 4.554 & 1.310 \\
\hline 09 & 1.070 & 1.130 & 1.090 & 0.286 & 0.553 & 0.398 & 4.165 & 4.665 & 5.368 & 18.331 & 23.440 & 34.885 \\
\hline 10 & 1.450 & 1.520 & 1.480 & 0.692 & 0.750 & 0.712 & 1.402 & 1.528 & 1.456 & 1.271 & 2.179 & 1.670 \\
\hline 11 & 1.820 & 1.460 & 1.690 & 0.854 & 0.721 & 0.828 & 0.836 & 1.469 & 1.013 & 0.003 & 1.374 & 0.272 \\
\hline 12 & 1.590 & 1.280 & 1.490 & 0.851 & 0.658 & 0.803 & 1.477 & 2.505 & 1.731 & 1.830 & 5.877 & 2.617 \\
\hline 13 & 1.130 & 1.040 & 1.100 & 0.418 & 0.282 & 0.379 & 3.689 & 8.737 & 4.558 & 14.887 & 85.319 & 23.545 \\
\hline 14 & 1.280 & 1.270 & 1.280 & 0.585 & 0.674 & 0.616 & 2.273 & 3.374 & 2.761 & 5.312 & 13.496 & 9.211 \\
\hline 15 & 1.110 & 1.070 & 1.100 & 0.346 & 0.331 & 0.341 & 3.217 & 4.800 & 3.688 & 10.421 & 23.392 & 13.954 \\
\hline 16 & 1.050 & 1.050 & 1.050 & 0.231 & 0.280 & 0.248 & 5.045 & 5.675 & 5.397 & 27.354 & 33.673 & 31.429 \\
\hline 17 & 1.050 & 1.110 & 1.070 & 0.265 & 0.452 & 0.341 & 5.592 & 5.776 & 6.375 & 33.143 & 40.698 & 51.830 \\
\hline 18 & 1.680 & 1.340 & 1.570 & 0.798 & 0.601 & 0.753 & 1.012 & 1.764 & 1.232 & 0.627 & 2.883 & 1.135 \\
\hline 19 & 1.320 & 1.210 & 1.280 & 0.567 & 0.536 & 0.558 & 1.742 & 3.070 & 2.126 & 2.635 & 10.572 & 4.643 \\
\hline 20 & 1.120 & 1.130 & 1.120 & 0.391 & 0.511 & 0.435 & 3.857 & 5.143 & 4.646 & 17.133 & 30.309 & 26.608 \\
\hline 21 & 1.100 & 1.130 & 1.110 & 0.345 & 0.600 & 0.448 & 3.637 & 5.073 & 5.252 & 13.575 & 26.878 & 33.372 \\
\hline 22 & 1.190 & 1.120 & 1.160 & 0.507 & 0.418 & 0.479 & 2.863 & 4.170 & 3.193 & 7.931 & 20.107 & 10.505 \\
\hline 23 & 1.190 & 1.120 & 1.170 & 0.474 & 0.401 & 0.451 & 2.505 & 3.510 & 2.769 & 5.593 & 12.112 & 7.067 \\
\hline 24 & 1.490 & 1.400 & 1.460 & 0.756 & 0.697 & 0.736 & 1.803 & 1.691 & 1.774 & 3.730 & 2.186 & 3.342 \\
\hline 25 & 1.550 & 1.440 & 1.510 & 0.740 & 0.691 & 0.725 & 1.133 & 1.665 & 1.290 & 0.495 & 2.653 & 1.039 \\
\hline 26 & 1.200 & 1.230 & 1.210 & 0.537 & 0.659 & 0.581 & 2.973 & 3.886 & 3.462 & 9.323 & 17.083 & 14.015 \\
\hline 27 & 1.260 & 1.260 & 1.260 & 0.546 & 0.638 & 0.578 & 2.400 & 2.722 & 2.555 & 6.642 & 7.124 & 6.981 \\
\hline 28 & 1.150 & 1.190 & 1.160 & 0.537 & 0.484 & 0.448 & 2.975 & 2.615 & 2.834 & 8.429 & 6.110 & 7.440 \\
\hline 29 & 1.150 & 1.170 & 1.160 & 0.423 & 0.499 & 0.450 & 2.856 & 3.301 & 3.083 & 7.790 & 11.337 & 9.780 \\
\hline 30 & 1.320 & 1.280 & 1.300 & 0.766 & 0.658 & 0.730 & 2.677 & 2.361 & 2.617 & 6.872 & 4.782 & 6.573 \\
\hline
\end{tabular}




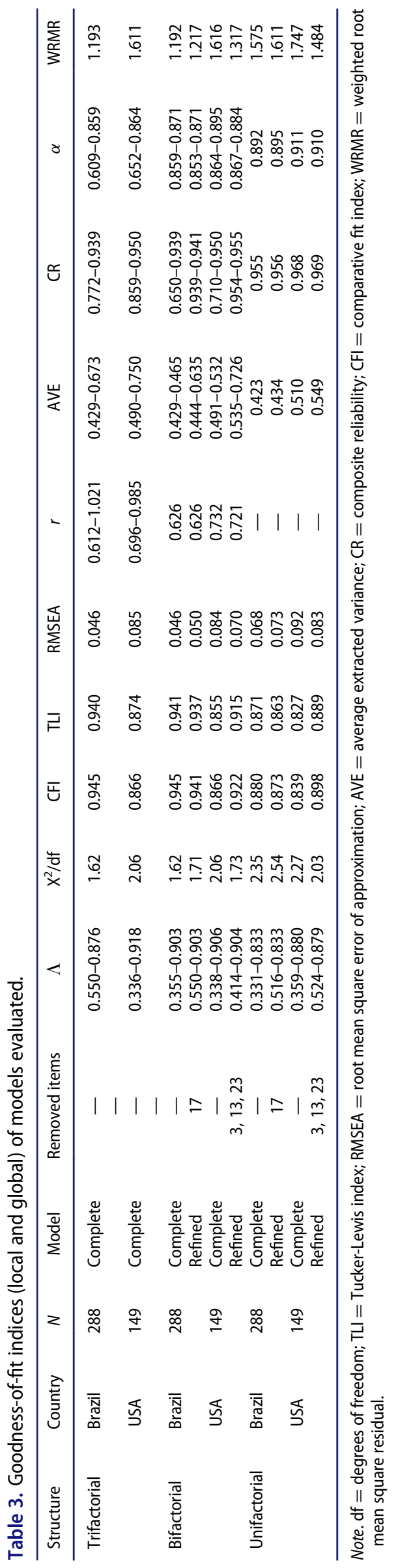


Table 4. Summary of structural equation modeling.

\begin{tabular}{|c|c|c|c|c|c|c|}
\hline Country & Factor & Variable & B & $\beta$ standardized & Standard error & $p$ value \\
\hline \multirow[t]{8}{*}{ Brazil } & Physical function & Gender & 0.434 & 0.336 & 0.067 & $<.001$ \\
\hline & & Academic year & 0.136 & -0.326 & 0.055 & $<.001$ \\
\hline & & Sports practices & 0.103 & -0.088 & 0.059 & 0.137 \\
\hline & & Work activities & 0.013 & 0.007 & 0.069 & .915 \\
\hline & Symptoms/social function & Gender & 0.351 & 0.156 & 0.074 & .028 \\
\hline & & Academic year & 0.066 & -0.098 & 0.072 & .173 \\
\hline & & Sports practices & 0.010 & -0.005 & 0.073 & .943 \\
\hline & & Work activities & 0.141 & 0.049 & 0.081 & .546 \\
\hline \multirow[t]{8}{*}{ USA } & Physical function & Gender & 0.087 & 0.104 & 0.101 & .307 \\
\hline & & Academic year & 0.025 & 0.066 & 0.112 & .555 \\
\hline & & Sports practices & 0.191 & -0.223 & 0.103 & .020 \\
\hline & & Work activities & 0.154 & -0.123 & 0.231 & .595 \\
\hline & Symptoms/social function & Gender & 0.057 & 0.035 & 0.108 & .747 \\
\hline & & Academic year & 0.065 & 0.088 & 0.122 & .473 \\
\hline & & Sports practices & 0.001 & -0.001 & 0.108 & .995 \\
\hline & & Work activities & 0.136 & 0.056 & 0.110 & .614 \\
\hline
\end{tabular}

$(\alpha \geq 0.7)$ in the trifactorial model in both countries and presented appropriate values in the remaining models.

On the basis of the data presented in Table 3, DASH's bifactorial structure was selected for use in the causal model with the Brazilian and American samples. The bifactorial and trifactorial models presented a good fit in Brazil; however, the trifactorial model was not used because of the multicollinearity between factors symptoms and social function $(r=1.021)$. Only the bifactorial model presented adequate local and global adjustments for the American samples.

Table 4 presents the contribution of the demographic variables evaluated on the latent DASH factors in the bifactorial model in each country.

There was a significant effect of the variables gender and academic year on the factor physical function and the variable gender on symptoms/social function in the Brazilian sample and the variable sports practices on physical function in the American sample.

Figure 1 presents the causal model of the variables with a significant contribution in the Brazilian sample.

The academic year influenced physical function in the Brazilian sample such that the higher the academic year, the lower was the level of disability (standardized $\beta=-0.326)$. Meanwhile, gender affected the factors physical function and symptoms/social function, and the female gender presented the highest degree of physical disability (standardized $\beta=0.336$ ) and symptoms/social function (standardized $\beta=0.156$ ).

Figure 2 presents the causal model of the variable with a significant contribution in the American sample.

In addition, only sports practices presented a significant contribution to physical function in the American samples, and individuals who practiced sports presented the lowest degrees of disability for this factor $(-0.223)$.

\section{Comment}

This transnational study evaluated the psychometric characteristics of the DASH scale in a normative population of dental students of Brazil and the United States and assessed the influence of gender, academic year, sports practices, and work activities on disability in both groups.

We used the classical theory for process validation, although Franchignoni et $\mathrm{al}^{31}{ }^{31}$ Cano et $\mathrm{al},{ }^{32}$ and Forget et $\mathrm{al}^{33}$ consider the Rasch analysis a more robust method. In the present study, 3 factorial proposals were tested for the DASH scale (uni, bi, and trifactorial), and since the Rasch analysis considers unidimensionality to be an important assumption, its use would not be feasible. Nevertheless, we used a strong program to validate the classical theory, which is considered a robust analysis; therefore, we believe data validity and reliability were ensured.

Most studies that applied the DASH scale used the unifactorial structure ${ }^{3,14,34-37}$ proposed by the authors. ${ }^{7,28}$ In this study, the unifactorial structure could not be adjusted for the Brazilian and American samples, even after refining. Cheng et $\mathrm{al}^{38}$ and Franchignoni et $\mathrm{al}^{31}$ found better data adjustment in the trifactorial model than in the present study, in which a high correlation was observed between 2 factors. Kennedy et $\mathrm{al}^{28}$ evaluated the psychometric properties of the unifactorial and bifactorial models during the development of DASH; although the bifactorial model was found to have better psychometric properties than the other models, some items were saturated in both factors, and therefore, the authors decided to use the unifactorial model. In our study, the refined bifactorial model presented the best fit for both Brazilian and American students. However, our study population could be considered normative. Most studies that used the DASH scale obtained data from a 


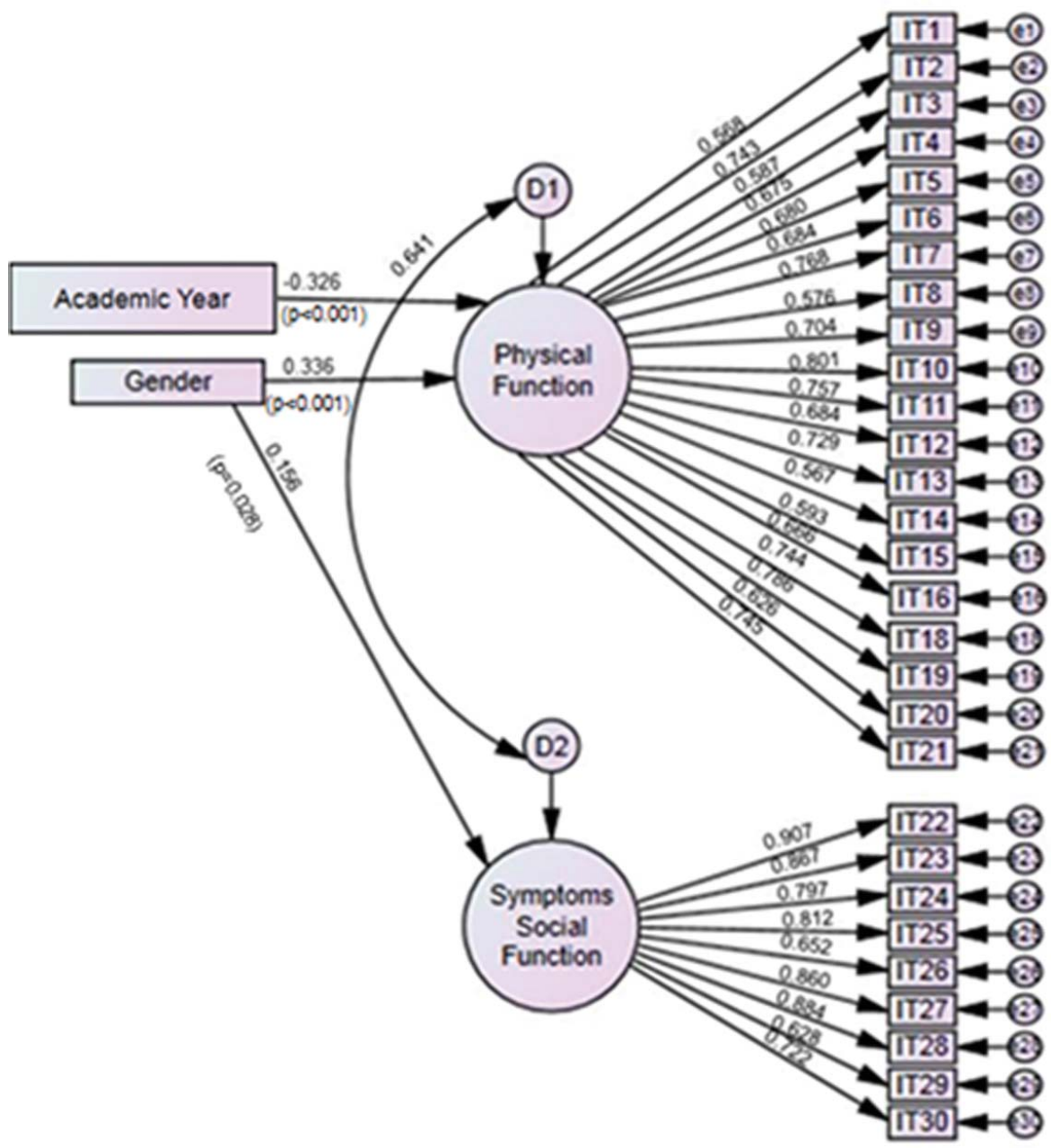

Figure 1. Causal model of Brazil with the significant contribution $(p<.05)$.

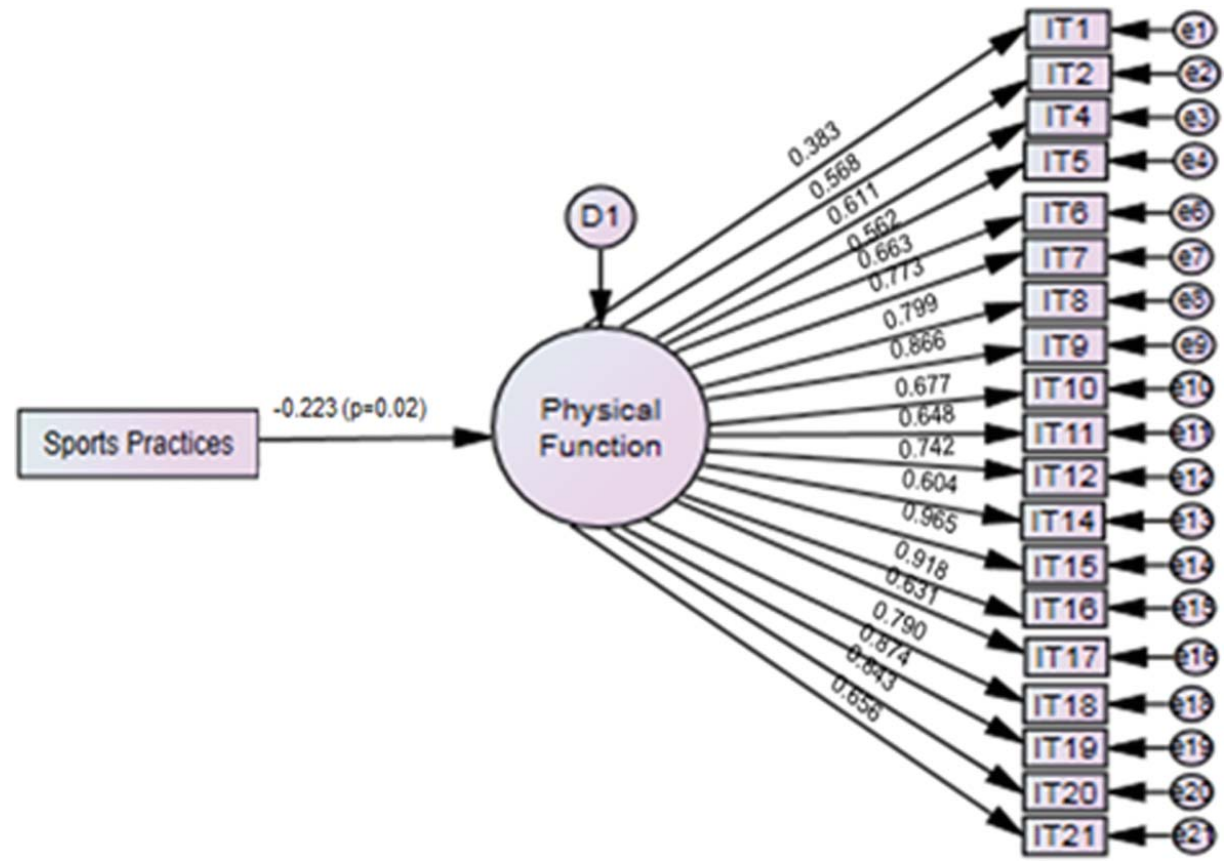

Figure 2. Causal model of the United States with a significant contribution $(p<.05)$. 
sample of individuals with musculoskeletal disorders in the upper limbs, which might explain the differences between the observed factorial structures.

A good fit of the models was achieved by removing some items. However, only the bifactorial model obtained a good fit for the Brazilian and American samples. For the Brazilian sample, it was necessary to remove item 17 (recreational activities), and for the American sample, items 3 (turning keys), 13 (washing/drying the hair), and 23 (limitation in work activities because of the DASH scale), which resulted in the development of bifactorial models with a different item structure.

The DASH scale characteristics were different in samples from different countries with the same demographic features. This result indicates the importance of a validation study, which should be conducted before the use of the instrument. Hunsaker et $\mathrm{al}^{39}{ }^{39}$ Cheng et $\mathrm{al},{ }^{38}$ Franchignoni et $\mathrm{al}^{31}{ }^{31}$ Lehman et $\mathrm{al}^{36}$ and Wang et $\mathrm{al}^{2}$ also found a lack of local fit for some items (change of light bulbs, gender activity, burning sensation on the skin, and difficulty sleeping and driving). Only Cheng et $\mathrm{al}^{38}$ excluded the item turning keys, and this item was removed from our models for the American population.

The item eliminated from the bifactorial model for the Brazilian sample relates to recreational activities and involves playing cards or knitting; this elimination can be explained by the characteristics of the study population, which belongs to a generation in which recreational activities are correlated primarily with the use of technology. In terms of the American sample, the students may have responded to the excluded items with "no difficulties were experienced" because they were considered easy to perform and this group did not have established musculoskeletal problems; in addition, this might have caused the "ceiling" effect, which, according to Forget et $\mathrm{al}^{33}$ might affect the capacity of measuring symptoms/ social function in the DASH scale.

The effect of sociodemographic variables on physical function and symptoms/social function in the bifactorial model was evaluated after the structural model of the DASH scale was validated in the Brazilian and American populations, and good reliability values were obtained (Table 3); however, these variables contributed differently to the DASH scale in the 2 populations.

For the Brazilian sample, the academic year presented a significant contribution $(p<.001)$ only for physical function, such that the higher the academic year, the lower was the disability. Meanwhile, gender contributed significantly to physical function $(p<.001)$ and symptoms/social function $(p=.028)$, and women reported higher degrees of physical disability and symptoms than men. Similar results were found in studies conducted by Cheng et $\mathrm{al}^{38}$ and Forget et al. ${ }^{33}$ Greenslade et al, ${ }^{40}$ Jester et $\mathrm{al}^{41}$ and Forget et $\mathrm{al}^{33}$ reported that these results might be explained by the items in the instrument because most items were related to domestic activities, which were primarily performed by women, including making the bed and domestic tasks. According to Hooftman et $\mathrm{al}^{42}$ a similar exposure to the same risk factor among men and women may have a greater effect on women due to biological differences (body size, muscular capacity, aerobic capacity, and hormonal conditions) or to psychological differences (such as coping strategies). ${ }^{43}$ De Zwart et $\mathrm{al}^{44}$ and Treaster and Burr ${ }^{45}$ emphasize that biological differences, the number of tasks besides work, the way the task is performed, and a work position based on male anthropometric measures can make women more susceptible to complaints in the upper limbs. Another point to be considered is the higher awareness of women about health issues, which may allow them to develop a broader perspective and report issues related to their health. ${ }^{42,44}$ In this study, the population studied was of university students, and therefore the issues related to domestic activities were not addressed.

Regarding the causal model obtained for American students, only sports practice had a significant effect on physical function $(p=.020)$ as sports practices were associated with lower scores. This result may be related to the American culture, which encourages students to participate in sports activities starting in elementary school, and according to Andersen et al, ${ }^{46}$ the practice of sports might act as a protective factor against the development of disabilities by strengthening the musculoskeletal system.

In this study, the DASH scale structure and the influence of the variables gender and academic year on the construct that it evaluates differed between American and Brazilian students. The original DASH questionnaire is in English and was developed considering the American culture settings. As such, for American students, the DASH scale was culturally adapted. For the Brazilian students, it was adapted culturally by Orfale et al. ${ }^{21}$ Thus, cultural differences were taken into account in the instruments applied to students of the 2 different countries. According to Atroshi et $a{ }^{14}{ }^{14}$ the process of transcultural adaptation allows the observed differences between populations of different countries to reflect differences in their health status rather than differences caused by the translation of the instrument. Therefore, observed differences between American and Brazilian students reflect their cultural and behavioral context.

The main limitation of this study is that the crosssectional design limits the possibility of observing causality between the variables. Thus, it is recommended that other studies with an analytical approach be conducted. Another possible limitation is the smaller sample size in 
the American population and the selection of a convenience sample, which may hamper the generalization of the results.

Despite these limitations, to date, no study has used this scale for dental professionals and students, who are very susceptible to musculoskeletal problems in the upper limbs, and thus, the present study helped fill this gap and may enable more researchers to address problems pertaining to disability in dental professionals. Another significant contribution of this study was its transnational nature, which makes this study unique. The results obtained here indicate the need for caution in the use of psychometric scales because we observed that the psychometric characteristics of the DASH scale were distinct in populations of different nationalities. Considering that appropriate psychometric properties (ie, values that are closest to reality) will minimize measurement errors, conducting validity studies is essential for obtaining reliable data, which will guarantee the adoption of effective preventive and educational strategies.

\section{Conclusion}

The refined bifactorial model was valid and reliable for the Brazilian and American populations. In this model, the removal of item 17 for the Brazilian sample and items 3, 13, and 23 for the American sample was necessary. In addition, demographic variables such as gender, academic year, and sports practice contributed significantly to the level of disability in the study populations.

\section{Acknowledgments}

The authors thank the students of Araraquara Dental School and Stony Brook University School of Dental Medicine volunteers of this study.

\section{Funding}

The authors thank the Coordenação de Aperfeiçoamento de Pessoal de Nível Superior (CAPES) for the Master's scholarship.

\section{ORCID}

Danielle Wajngarten (D) http://orcid.org/0000-0002-0090-3459

\section{References}

1. Fan ZJ, Smith CK, Silverstein BA. Assessing validity of the QuickDASH and SF-12 as surveillance tools among workers with neck or upper extremity musculoskeletal disorders. J Hand Ther. 2008;21:354-365.
2. Wang Y, He Z, Lei L, et al. Reliability and validity of the Chinese version of the Short Musculoskeletal Function Assessment questionnaire in patients with skeletal muscle injury of the upper or lower extremities. BMC Musculoskelet Disord. 2015;16:161. doi:10.1186/s12891-015-0617-z.

3. Kitis A, Celik E, Aslan UB, Zencir M. DASH questionnaire for the analysis of musculoskeletal symptoms in industry workers: a validity and reliability study. App Ergon. 2009;40:251-255.

4. Bot SDM, Terwee CB, van der Windt DAWM, Bouter LM, Dekker J, de Vet HCW. Clinimetric evaluation of shoulder disability questionnaires: a systematic review of the literature. Ann Rheum Dis. 2004;63:335-341.

5. Beaton DE, Wright JG, Katz JN; Upper Extremity Collaborative Group. Development of the QuickDASH: comparison of three item-reduction approaches. J Bone Joint Surg. 2005;87:1038-1046.

6. Gabel CP, Yelland M, Melloh M, Burkett B. A modified QuickDASH-9 provides a valid outcome instrument for upper limb function. BMC Musculoskelet Disord. 2009;10:161.

7. Hudak PL, Amadio PC, Bombardier C. Development of an upper extremity outcome measure: the DASH (disabilities of the arm, shoulder, and hand). The Upper Extremity Collaborative Group (UECG). Am J Ind Med. 1996;30:372.

8. Kuorinka I, Jonsson B, Kilbom A, Vinterberg H. Standardised Nordic questionnaires for the analysis of musculoskeletal symptoms. App Ergon. 1987;18:233-237.

9. Wong JY, Fung BK, Chu MM, Chan RK. The use of Disabilities of the Arm, Shoulder, and Hand questionnaire in rehabilitation after acute traumatic hand injuries. $J$ Hand Ther. 2007;20:49-56.

10. Jodalli PS, Kurana S, Ragher M, Khed J, Prabhu V. Posturedontics: how does dentistry fit you? J Pharm Bioallied Sci. 2015;7:S393-S397. doi:10.4103/0975-7406.163463.

11. Maroco J. Analysis of structural equations [in Portuguese]. Lisbon: Pero Pinheiro; 2010: 374 p.

12. Campos JADB, Zucoloto ML, Bonafé FSS, Jordani PC, Maroco J. Reliability and validity of self-reported burnout in college students: a cross randomized comparison of paper-and-pencil vs online administration. Comput Hum Behav. 2011;27:1875-1883.

13. Campos JADB, Maroco J. Maslach Burnout inventory-student survey: Portugal-Brazil cross-cultural adaptation. Revista de Saúde Pública. 2012;46:816-824.

14. Atroshi I, Gummesson C, Andersson B, Dahlgren E, Johansson A. The Disabilities of the Arm, Shoulder and Hand (DASH) outcome questionnaire: reliability and validity of the Swedish version evaluated in 176 patients. Acta Orthop Scand. 2000;71:613-618.

15. Dubert T, Voche P, Dumontier C, Dihn A. Le questionnaire DASH. Adaptation francaise d'un outil d'evaluation international. Chir Main. 2001;20:294-302.

16. Gummesson C, Atroshi I, Ekdahl C. The Disabilities of the Arm, Shoulder and Hand (DASH) outcome questionnaire: Longitudinal construct validity and measuring self-rated health change after surgery. BMC Musculoskelet Disord. 2003;4:1-6.

17. Jeon SH, Lee JH, Chung MS, et al. Responsiveness of the Korean version of the Disabilities of the Arm, Shoulder and Hand questionnaire (K-DASH) after carpal tunnel release. Clin Orthop Surg. 2011;3:147-151. doi:10.4055/ cios.2011.3.2.147. 
18. Lee JY, Lim JY, Oh JH, Ko YM. Cross-cultural adaptation and clinical evaluation of a Korean version of the Disabilities of Arm, Shoulder, and Hand outcome questionnaire (K-DASH). J Shoulder Elbow Surg. 2008;17:570-574.

19. Liang HW, Wang HK, Yao G, Horng YS, Hou SM. Psychometric evaluation of the Taiwan version of the Disability of the Arm, Shoulder and Hand (DASH) questionnaire. J Formos Med Assoc. 2004;103:773-779.

20. Offenbächer M, Ewert T, Sangha O, Stucki G. Validation of a German version of the "Disabilities of Arm, Shoulder and Hand" questionnaire (DASH-G). Z Rheumatol. 2003;62:168-177.

21. Orfale AG, Araújo PMPD, Ferraz MB, Natour J. Translation into Brazilian Portuguese, cultural adaptation and evaluation of the reliability of the Disabilities of the Arm, Shoulder and Hand questionnaire. Braz J Med Biol Res. 2005;38:293-302.

22. Rosales RS, Delgado EB, de la Lastra-Bosch ID. Evaluation of the Spanish version of the DASH and carpal tunnel syndrome health-related quality-of-life instruments: crosscultural adaptation process and reliability. J Hand Surgery. 2002;27A:334-343.

23. Garcia PPNS, Pinelli C, Derceli JDR, Campos JADB. Musculoskeletal disorders in upper limbs in dental students: exposure level to risk factors. Braz J Oral Sci. 2012;11:148-153.

24. Garcia PP, Presoto CD, Maroco J, Campos JA. Workrelated activities that may contribute to musculoskeletal symptoms among dental students: validation study. J Phys Ther Sci. 2015;27:3651-3654. doi:10.1589/jpts.27.3651.

25. Kim KS, Kim MG. Gender-related factors associated with upper extremity function in workers. Saf Health Work. 2010;1:158-166. doi:10.5491/SHAW.2010.1.2.158.

26. Movahhed T, Dehghani M, Arghami S, Arghami A. Do dental students have a neutral working posture? J Back Musculoskelet Rehabil. 2016;29:859-864.

27. Kim KH. The relation among fit indexes, power, and sample size in structural equation modeling. Structural Equation Modeling. 2005;12:368-390.

28. Kennedy CA, Beaton DE, Solway S, McConnell S, Bombardier C. The DASH and QuickDASH Outcome Measure User's Manual. 3rd ed. Toronto, Ontario: Institute for Work \& Health; 2011.

29. Hill MM, Hill A. Investigação por questionário. Lisbon: Edições Sílabo 2005: 377.

30. Fornell C, Larker DF. Evaluating structural equation models with unobservable variables and measurement error: algebra and statistics. J Mark Res. 1981;18:382-388.

31. Franchignoni F, Giordano A, Sartorio F, Vercelli S, Pascariello B, Ferriero G. Suggestions for refinement of the Disabilities of the Arm, Shoulder and Hand Outcome Measure (DASH): a factor analysis and Rasch validation study. Arch Phys Med Rehabil. 2010;9:1370-1377. doi:10.1016/j.apmr.2010.06.022.

32. Cano SJ, Barrett LE, Zajicek JP, Hobart JC. Beyond the reach of traditional analyses: using Rasch to evaluate the DASH in people with multiple sclerosis. Mult Scler. 2011;17:214-222. doi:10.1177/1352458510385269.

33. Forget NJ, Jerosch-Herold C, Shepstone L, Higgins J. Psychometric evaluation of the Disabilities of the Arm, Shoulder and Hand (DASH) with Dupuytren's contracture: validity evidence using Rasch modeling. BMC Musculoskelet Disord. 2014;30:361. doi:10.1186/ 1471-2474-15-361.

34. Chen H, Ji X, Zhang W, Zhang Y, Zhang L, Tang P. Validation of the simplified Chinese (Mainland) version of the Disability of the Arm, Shoulder, and Hand questionnaire (DASH-CHNPLAGH). J Orthop Surg Res. 2015;10:76. doi:10.1186/s13018-015-0216-6.

35. Haldorsen B, Svege I, Roe Y, Bergland A. Reliability and validity of the Norwegian version of the Disabilities of the Arm, Shoulder and Hand questionnaire in patients with shoulder impingement syndrome. BMC Musculoskelet Disord. 2014;12:78. doi:10.1186/14712474-15-78.

36. Lehman LA, Woodbury M, Velozo CA. Examination of the factor structure of the Disabilities of the Arm, Shoulder, and Hand questionnaire. Am J Occup Ther. 2011;65:169-178.

37. Mousavi SJ, Parnianpour M, Abedi M, et al. Cultural adaptation and validation of the Persian version of the Disabilities of the Arm, Shoulder and Hand (DASH) outcome measure. Clin Rehabil. 2008;22:749-757. doi:10.1177/ 0269215508085821.

38. Cheng HM, Sampaio RF, Mancini MC, Fonseca ST, Cotta RM. Disabilities of the Arm, Shoulder and Hand (DASH): factor analysis of the version adapted to Portuguese/Brazil. Disabil Rehabil. 2008;30:1901-1909. doi:10.1080/09638280701749342.

39. Hunsaker FG, Cioffi DA, Amadio PC, Wright JG, Caughlin B. The American Academy of Orthopaedic Surgeons outcomes instruments: normative values from the general population. J Bone Joint Surg Am. 2002;84A:208-215.

40. Greenslade JR, Mehta RL, Belward P, Warwick DJ. Dash and Boston Questionnaire Assessment of Carpal Tunnel Syndrome Outcome: what is the responsiveness of an outcome questionnaire? J Hand Surg. 2004;29B:159-164.

41. Jester A, Harth A, Wind G, Germann G, Sauerbier M. Disabilities of the Arm, Shoulder and Hand (DASH) questionnaire: determining functional activity profiles in patients with upper extremity disorders. J Hand Surg Br. 2005;30:23-28.

42. Hooftman WE, van Poppel MN, van der Beek AJ, Bongers $\mathrm{PM}$, van Mechelen W. Gender differences in the relations between work-related physical and psychosocial risk factors and musculoskeletal complaints. Scand J Work Environ Health. 2004;30:261-278.

43. Coury HJCG, Porcatti IA, Alem ME, Oishi J. Influence of gender on work-related musculoskeletal disorders in repetitive tasks. Int J Ind Ergon. 2002;29:33-39.

44. De Zwart BCH, Frings-Dresen MHW, Kilbom A. Gender differences in upper extremity musculoskeletal complaints in the working population. Int Arch Occup Environ Health. 2001;74:21-30.

45. Treaster DE, Burr D. Gender differences in prevalence of upper extremity musculoskeletal disorders. Ergonomics. 2004;47:495-526.

46. Andersen LL, Kjaer M, Sögaard K, Hansen L, Kryger AI, Sjögaard G. Effect of two contrasting types of physical exercise on chronic neck muscle pain. Arthritis Care Res. 2008;59:84-91. 